This item was submitted to Loughborough's Research Repository by the author.

Items in Figshare are protected by copyright, with all rights reserved, unless otherwise indicated.

\title{
Algorithms for digital control
}

PLEASE CITE THE PUBLISHED VERSION

PUBLISHER

(C) W. Forsythe et al.

\section{PUBLISHER STATEMENT}

This work is made available according to the conditions of the Creative Commons Attribution-NonCommercialNoDerivatives 4.0 International (CC BY-NC-ND 4.0) licence. Full details of this licence are available at: https://creativecommons.org/licenses/by-nc-nd/4.0/

\section{LICENCE}

CC BY-NC-ND 4.0

REPOSITORY RECORD

Forsythe, William. 2019. “Algorithms for Digital Control”. figshare. https://hdl.handle.net/2134/28050. 


\section{Loughborough University}

This item was submitted to Loughborough University as a PhD thesis by the author and is made available in the Institutional Repository

(https://dspace.lboro.ac.uk/) under the following Creative Commons Licence conditions.

\section{cc) creative}

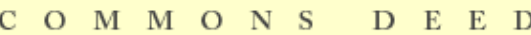

Attribution-NonCommercial-NoDerivs 2.5

You are free:

- to copy, distribute, display, and perform the work

Under the following conditions:

Attribution. You must attribute the work in the manner specified by the author or licensor.

Noncommercial. You may not use this work for commercial purposes.

No Derivative Works. You may not alter, transform, or build upon this work.

- For any reuse or distribution, you must make clear to others the license terms of this work.

- Any of these conditions can be waived if you get permission from the copyright holder.

Your fair use and other rights are in no way affected by the above.

This is a human-readable summary of the Leqal Code (the full license).

Disclaimer 민

For the full text of this licence, please go to: http://creativecommons.org/licenses/by-nc-nd/2.5/ 


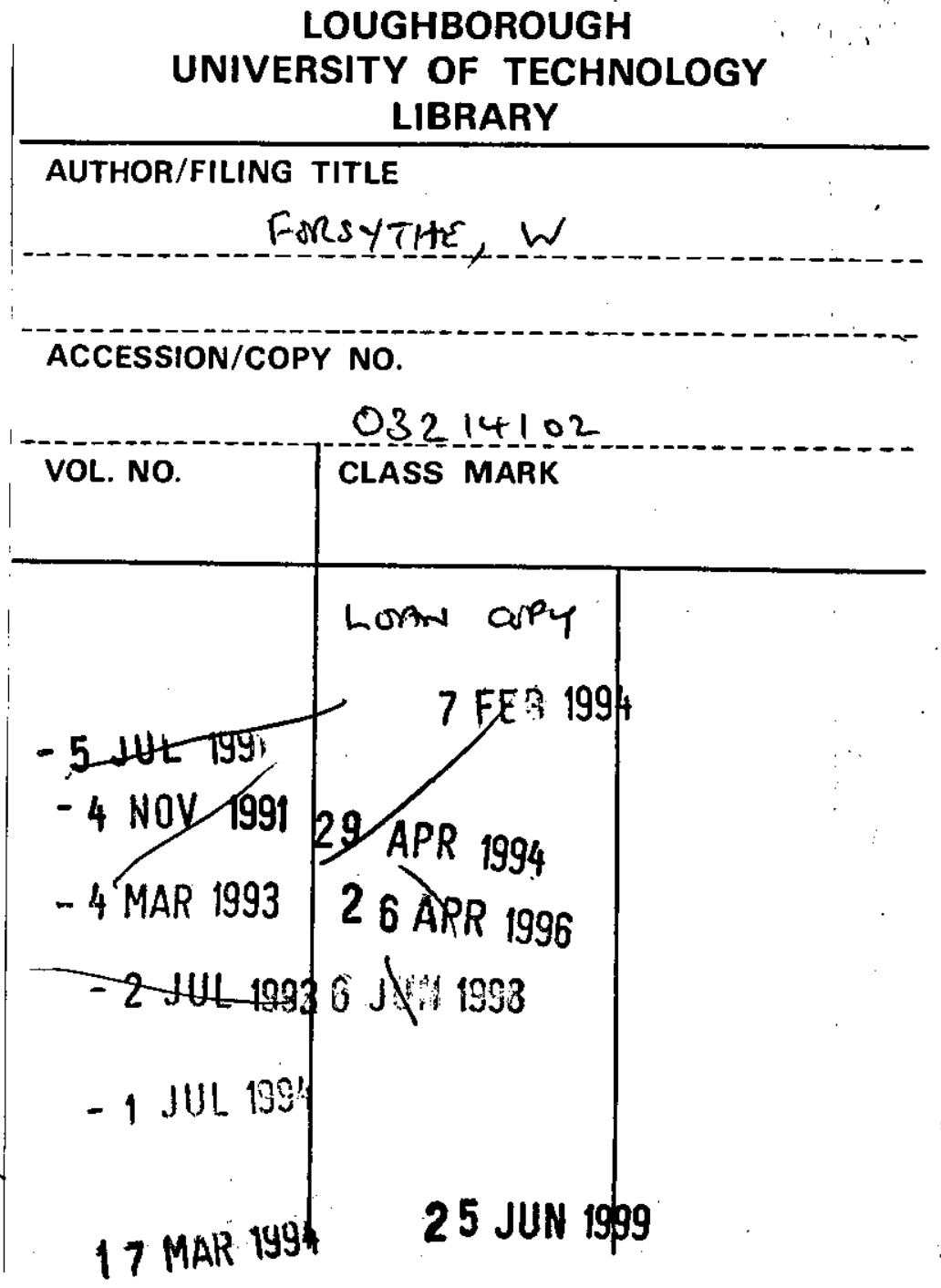

$003 \quad 2141 \quad 02$

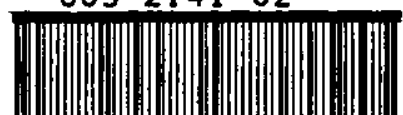





\title{
Algorithms for Digital Control
}

\author{
by \\ W.Forsythe, B.Sc., M.Sc.
}

A doctoral thesis

submitted in partial fulfilment of the requirements

for the award of

the degree of Doctor of Philosophy of the

Loughborough University of Technology

September, 1988

Department of Electronic and Electrical Engineering

Loughborough University of Technology

๑ W. Forsythe 


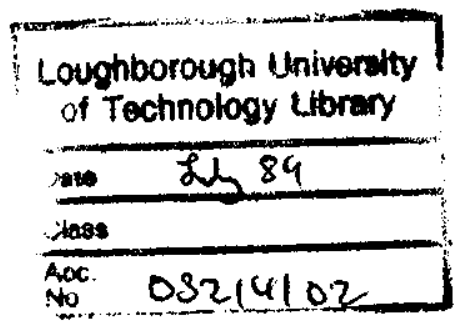




\section{Algorithms for Digital Control}

\section{Synopsis}

Eight papers are presented describing work published over more than a decade dealing with the design and performance of digital control algorithms.

Oxiginating in a study undertaken with the train control group at the Railway Technical Centre, Derby, the first paper presents the derivation of digital algorithms for the computation of integrals, derivatives, and predicted values. This is carried out in a novel manner that lends itself among other things to the ready evaluation of computational error, which is seen in two further papers to depend upon complexity of the algorithm, processor word-length, sampling frequency, and other factors. These interact in a complex but quantifiable manner that leads to a choice of system_parameter values designed to minimize computational error, as illustrated in a number of case studies.

The question is then asked whether the basis for such an analysis can be extended to cover any linear difference equation or transfer function. The answer essentially constitutes the remainder of the text.

To extend the method of derivation given in Paper one, a number of conceptual difficulties must be overcome, and this is described in Papers four five and six, while the seventh paper develops the generalized truncation (or discretization) error analysis first set out in Papers two and three for specific cases.

A final paper discusses the evaluation of quantization error in the general case and thus completes the extension of the original error analysis. 


\section{PREFACE}

The work covered in the eight papers that comprise this volume began when I was engaged with the Train Control Group at the Rallway Technical Centre, Derby, in a study of the Driverless Train concept. This proved to be entirely feasible and was in fact engineered to the point where plans were being drawn up for a limited trial in public service when the project was cancelled. The first three papers relate directly to a small part of that effort: the determination of a vehicle's speed and acceleration from a stream of pulses generated by an axle mounted disc. The work reported in the papers is in fact more general than this, embracing integration and prediction algorithms as well as those for differentiation. The first paper determines the necessary algorithms, which are of course not new; what is new, and quite elegant, is the method of their determination. The following two papers examine the errors, both discretization (truncation) and quantization, that are inherent in their use and ask how these relate to computer word length and sampling interval. The relationship is complex but proves to be quantifiable and leads to a choice of sampling interval that will minimize errors, on the assumption of maximum values for speed, acceleration, and jerk, which in the context of a train are known with reasonable certainty.

The question that is studied in the remaining papers is essentially whether or not such a profitable analysis can be extended to cover mathematical functions other than integration and differentiation.

The fourth paper makes a start by extending the method described in the first paper for deriving digital algorithms to include any linear differential equation, not just integration and differentiation. The new method is found to function better as more samples are incorporated in the algorithm but when the samples are few it does not in fact work well.

The fifth and sixth papers remedy the deficiency of the fourth and offer a number of interesting comparisons in performance.

The method of deriving the algorithm, that has been developed in papers three to six, also presents a ready means of evaluating the assoclated discretization error, it is shown in the seventh paper that this method of evaluation is in fact applicable to all digital algorithms whatever their 
derivation and some comparisons are made between algorithms of different orlgins (pole-zero mapping, bilinear transformation, etc) on the basis of their discretization errors.

The eighth and final paper complements the seventh by examining sources of quantization error for the general digital fllter. In particular it assesses the effect of reducing the sampling interval on the various sources of quantization error, taking into account filter structure by considering three different forms.

Thus the aim in writing this series of papers has come to be largely realized: any s-domain transfer function can be represented in the z-domain using what is basically the Taylor expansion method of paper one, and the resulting algorithms have been analysed to produce expressions for discretization and quantization errors.

The third paper will be seen to have three authors, but the division of labour between Messrs Thomas, Kilroy and myself is clear - their contribution is confined to the case study that forms the latter portion of the paper.

The papers brought together here have been published at intervals in various journals, and at each publication it has been necessary, for the readers benefit, to review the relevant background material. The result of this is a somewhat tiresome, albeit unavoidable, repetition of certain material in a number of the papers; I can only ask the readers forbearance. 


\section{THE CONTEXT}

The papers included in this volume may be vlewed in the larger context of the authors work as a whole, which ranges widely over the general areas of simulation and control.

About ten papers have been, or are about to be, published on varlous aspects of simulation ranging from simulator design and performance to the choice of algorithm for modelling a given transfer function.

Closely related to this are the papers included in these pages on error mechanisms in digital algorithms and their dependence on word length, sampling frequency etc; this is obviously pertinent to both simulation and control interests.

A further group of papers investigates the application of theory to the control of trains and of ship navigation, while papers are in preparation on land navigation and on a design methodology for the control of multivariable systems.

At the time of writing, twenty three papers have been published in refereed journals and a further seven have been submitted or are in preparation. See the attached Bibliography. 


\section{LIST OF CONTENTS}

Paper:

Digital algorithms for prediction, differentlation and integration:

Part I Determination of the algorithm.

Part II Error analysis, prediction and Integration algorithms.

Part III Error analysis for differentiation algorithms.

Algorithms for digital control.

5

A new method for the computation of digital filter coefficients : Part I.

6.

A new method for the computation of digital filter coefficients : Part II.

Determination of the truncation error in difference equations.

8.

Quantization errors in digital filters and their dependence on sampling frequency. 


\section{Final Comments}

The papers offered in the preceding pages made a significant contribution to our understanding of digital algorithms, and their behaviour, in a number of ways.

The first paper presented an approach to the derivation of algorithms for integration and differentiation that was at once unifying, elegant, and original. In addition, the method greatly facilitated the determination of the expression for discretization (truncation) error and lead to the error analysis that was undertaken in papers 2 and 3; this too was new.

The fourth paper explained how the ideas developed in paper 1 could be extended beyond the narrow confines of integration and differentiation. The method whereby this was achieved was another innovative feature.

The fifth paper offered a refinement, a substantial one, to the basic method devised in paper 4. Both this paper and the next 1llustrated the method's value in a number of applications by comparing frequency responses with those obtained using the well tried bilinear transform.

The contribution of the seventh paper was to show that the means of deriving the discretization error, explained in papers 2 and 3 for integration and differentiation, could be extended readily to cover all linear algorithms or difference equations, however derived. This is clearly an important generalization.

The final paper complemented the work on the generalized discretization error by examining sources of quantization error, again in the general case.

Prior to publication of the penultimate paper of this series, little or nothing had been written on the topic of discretization error. Much, on the other hand, had been written on quantization error in its various guises, but: despite this attention, significant questions remained unanswered: how does filter structure affect quantization error, which types of quantization error increase with sampling frequency and which decrease? These and other important questions were addressed in the final paper, some of the answers may have been surprising. 
The work reported here could be usefully extended in at least two ways.

1) The results quoted on discretization error (paper 7) include a means of determining algorithm coefficients in such a way that discretization error is independent of the first $n+1$ derivatives of the input (or output) waveform, where $\mathrm{n}$ is the sum of the orders of numerator and denominator. Since alternative methods allow only that $n$ is equal to (or less than) the order of the numerator, such an algorithm might be expected to give a superior performance. Does it? What is meant by superior? Why do algorithms that map the s-plane poles best reproduce the s-plane frequency response when they don't map the s-plane zeroes?

ii) The expressions given for evaluation of discretization and quantization error could be employed in the manner of papers 2 and 3 to investigate the options in devising a practical scheme of control for a large plant. In such a situation approximate values for maximum rates of change may be available or could be assessed, allowing rough estimation of the discretization error. In a digital controller. Sufficient knowledge would be avallable to evaluate quantization errors so that the interaction of sampling interval, word length, etc, could be assessed and significent conclusions reached about the processing power needed for the job. 


\begin{tabular}{|c|c|c|}
\hline Forsythe W & $\begin{array}{l}\text { Critique of a new } \\
\text { digital differential } \\
\text { analyser. }\end{array}$ & $\begin{array}{l}\text { Simulation, February } \\
\text { 1975, pp 97-102. }\end{array}$ \\
\hline $\begin{array}{l}\text { Forsythe W } \\
\text { Houseman S L }\end{array}$ & $\begin{array}{l}\text { Integrator design for } \\
\text { a differential analyser }\end{array}$ & $\begin{array}{l}\text { The Electronic \& Radio } \\
\text { Radio Engineer, } \\
\text { December 1976, } \\
\text { pp 593-604. }\end{array}$ \\
\hline Forsythe W & $\begin{array}{l}\text { Pt I: Digital algorithms } \\
\text { for prediction, } \\
\text { integration and } \\
\text { differentiation }\end{array}$ & $\begin{array}{l}\text { Pransactions of the } \\
\text { Institute of } \\
\text { Measurement and } \\
\text { Control, January } 1979 \\
\text { pp 46-56. }\end{array}$ \\
\hline Forsythe $w$ & $\begin{array}{l}\text { Pt II: Errors in } \\
\text { prediction and } \\
\text { integration algorithms. }\end{array}$ & $\begin{array}{l}\text { April 1979, } \\
\text { pp 97-103. }\end{array}$ \\
\hline $\begin{array}{l}\text { Forsythe } \\
\text { Milroy I P } \\
\text { Thomas P D }\end{array}$ & $\begin{array}{l}\text { Pt III: Errors in } \\
\text { differentiation } \\
\text { algorithms. }\end{array}$ & $\begin{array}{l}\text { July 1979, } \\
\text { pp 154-158. }\end{array}$ \\
\hline Forsythe W & $\begin{array}{l}\text { The analogue computer } \\
\text { in digital form. }\end{array}$ & $\begin{array}{l}\text { Mathematics and } \\
\text { Computers in Simulation } \\
\text { December 1980, } \\
\text { pp } 330-339 .\end{array}$ \\
\hline $\begin{array}{l}\text { Forsythe W \& } \\
\text { Marshall W G }\end{array}$ & $\begin{array}{l}\text { Self-checking } \\
\text { multiprocessor module } \\
\text { for onboard train } \\
\text { operation. }\end{array}$ & $\begin{array}{l}\text { Electronics Letters, } \\
\text { July 1981, } \\
\text { pp 408-409. }\end{array}$ \\
\hline $\begin{array}{l}\text { Forsythe W \& } \\
\text { Morse M J }\end{array}$ & $\begin{array}{l}\text { Bit-slice implementation } \\
\text { of analogue-type } \\
\text { computing units. }\end{array}$ & $\begin{array}{l}\text { Journal of } \\
\text { Microprocessor } \\
\text { Applications 6, } \\
\text { pp 217-224, July } 1982 .\end{array}$ \\
\hline $\begin{array}{l}\text { Forsythe W \& } \\
\text { Marshall W G }\end{array}$ & $\begin{array}{l}\text { Microcomputers in } \\
\text { automatic train control } \\
\text { Pt I: Computer } \\
\text { reliability and } \\
\text { redundancy. }\end{array}$ & $\begin{array}{l}\text { Proc. Inst Mech Eng, } \\
\text { December 1982, } \\
\text { pp } 417-424 .\end{array}$ \\
\hline $\begin{array}{l}\text { Forsythe W \& } \\
\text { Marshall W G }\end{array}$ & $\begin{array}{l}\text { Pt II: Practical } \\
\text { considerations. }\end{array}$ & $\begin{array}{l}\text { Proc. Inst Mech Eng, } \\
\text { December } 1982 \text {, } \\
\text { pp } 425-431 .\end{array}$ \\
\hline
\end{tabular}


Forsythe w

Forsythe $\mathrm{W} \&$ Lim C C

Forsythe $\mathrm{W}$ \& $\operatorname{Lim} \mathrm{C} C$

Forsythe $W$ \& Marshall W G

Forsythe $W$ \& Milroy I P

Forsythe W

Forsythe w

Forsythe w Danisman $\mathrm{H}$ Eissa M A

Forsythe $w$ Sherit K I Self A W

Forsythe W

Forsythe W \& Thomas P D

Forysthe W

Forsythe W
Algorithms for digital control.

An autopilot for ship control.

Pt I: Design

considerations.

Pt II: Simulation studies

Cyclone I: A selfchecking control oriented multiprocessor.

rime-keeping control of an automatically driven train.

A new method for the computation of digital filter coefficients. Pt I: Fundamentals.

A new method for the computation of digital filter coefficients. Pt II: Interpolating and extrapolating.

Study of the closed loop structure of multivariable feed back control systems.

Digital compensation:

a comparison of methods.

Determination of the truncation error in difference eqns.

Control parameters for automated driving of guided vehicles.

Modelling mechanical networks

Quantization error in digital filters and their dependence on sampling frequency
Trans Inst Measurement and Control, September 1983, pp 123-135.

Proc. Inst Elec Eng, November 1983, pp 281-287.

Proc. Inst Elec Eng, November 1983 , pp 288-294.

Software and Microsystems, August 1983, pp 103-110.

Transportation Research, Pt B, August 1984, pp 459-468.

Simulation, January 1985, pp 23-31.

Simulation, February 1985, pp 75-80.

Trans Inst M.C., December 1985, pp 251-261.

Trans I.M.C., June 1985 , pp 117-126.

Applied math. modelling, october 1986, pp 367-375.

Journal of Dynamic Systems, Amer. Soc. Mech Eng, to be published.

Simulation to be published.

Trans. Inst. Measurement and Control, to be published. 


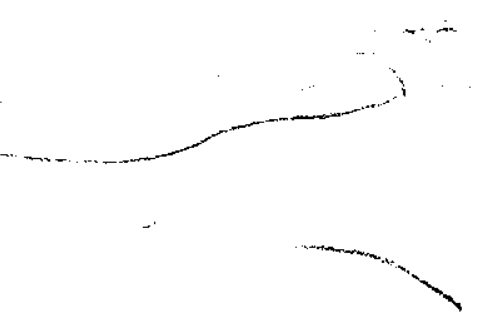

